\title{
INFRACCIÓN DE DEBER Y AUTORÍA - UNA CRÍTICA A LA TEORÍA DEL DOMINIO DEL HECHO*
}

\author{
Duty violation and primary criminal participation. Critical approach of the \\ doctrine of deed-control
}

Prof. Dr. Urs Kindhäuser, Bonn ${ }^{* *}$

\begin{abstract}
Resumen: El artículo revisa críticamente la así llamada "teoría del dominio del hecho" (Tatherrschaftlebre), sosteniendo que ésta no puede ofrecer un criterio plausible para la atribución de responsabilidad a título de autoría. Después de sentar las bases para una propuesta conceptual diversa, fundada en las nociones de norma, deber y acción, el artículo examina la manera en que semejante modelo puede contribuir a clarificar la estructura de formas más complejas de responsabilidad jurídico-penal, incluido aquí no sólo el ámbito de la intervención delictiva en su conjunto, sino también de la imprudencia.
\end{abstract}

Palabras clave: dominio del hecho, norma, deber, acción, autoría y participación, imprudencia

\begin{abstract}
The article critically reviews the so called "doctrine of deed-control" (Tatherrschaftlebre), arguing that it cannot offer a plausible criterion for the attribution of primary criminal responsibility. After setting forward a different conceptual proposal, grounded on a the notions of norm, duty and action, the article examines the way in which such a model can help to clarify the structure of more complex forms of criminal responsibility, including not only the complete realm of complicity but also criminal negligence.
\end{abstract}

Key words: deed-control, norm, action, duty, complicity, negligence

\section{LA TEORÍA SUBJETIVA DE LA INTERVENCIÓN DELICTIVA}

1. En derecho penal no sólo es responsable aquel que comete el delito solo y de propia mano, sino también aquel que lo comente conjuntamente con otros. La comisión conjunta de un delito recibe la denominación de "intervención", y ésta puede tener lugar, a su vez, en dos formas diferentes: en la forma de una autoría y en la forma de una participación.

\footnotetext{
* Traducción de Juan Pablo Mañalich R.

** Doctor en Derecho en la Albert-Ludwigs-Universität Freiburg. Venia Legendi por la AlbertLudwigs-Universität Freiburg. Catedrático y Director del Instituto de Derecho Penal de la Rheinische Friedrich-Wilhelms-Universität Bonn. Profesor honorario de la Universidad de Piura. Doctor honoris causa en la Universidad de Huánuco. Correo electrónico: Kindhauser@uni-bonn.de
} 
Junto al autor directo, también es autor el que comete el hecho como coautor, esto es, en conjunto con uno o varios otros autores, así como el que lo comete como autor mediato, esto es, a través del comportamiento de otra persona. En cambio, es partícipe aquel que o bien determina, como inductor, o bien auxilia, como cómplice, al autor que comete el hecho.

El Código Penal alemán asocia consecuencias jurídicas, correspondientes a diferentes grados de gravedad, a las distintas formas de intervención. Al autor directo, al coautor y al autor mediato resulta aplicable la misma medida de pena. El inductor puede ser penado de modo equivalente al autor, pero en la praxis judicial usualmente es sentenciado de modo más benigno. La pena aplicable al cómplice, en cambio, ha de ser necesariamente más baja, por imperativo legal. De ello se sigue que la demarcación entre autoría y participación es de máxima importancia práctica. Esta importancia se ve acrecentada, además, por el hecho de que bajo el derecho alemán la tentativa de complicidad no es punible. Y en la inducción la tentativa sólo es punible, adicionalmente, si ella se halla referida a un crimen y no, en cambio, si su objeto es un simple delito.

Esta diferenciación de formas de intervención constitutivas de autoría y participación rige exclusivamente tratándose de delitos dolosos. Los delitos imprudentes, en cambio, sólo conocen una forma de comisión, la autoría. Se habla, en esta medida, de un "autor unitario" en los delitos imprudentes. Así, quien imprudentemente hace algo que, de haber dolo, sólo podría calificarse de complicidad, es de todas formas autor del correspondiente delito imprudente.

2. Para la demarcación de la autoría y la participación, la jurisprudencia alemana recurre a una tesis sumamente simple. Si de conformidad con la así llamada teoría de la equivalencia, todas las condiciones necesarias para un resultado son equivalentes en tanto causas, entonces no es posible diferenciar la autoría y la participación de modo puramente objetivo. A modo de ejemplo: si A dispara con un arma contra $\mathrm{B}$, entonces no sólo el disparo, sino toda otra condición que no pueda ser mentalmente suprimida sin que el resultado desaparezca, es una causa para la muerte de B, lo cual quiere decir: también lo son la fabricación del arma, su compra, etc. Bajo una consideración puramente objetiva, tanto el tirador, el fabricante y el vendedor del arma serían autores de un homicidio.

Dado que este resultado sería evidentemente absurdo, la jurisprudencia alemana ha buscado una vía de escape en un criterio puramente subjetivo para la diferenciación de la autoría, la participación y otras formas de comportamiento jurídico-penalmente irrelevantes. Según esto, sería autor quien actúa con la voluntad de ser autor, esto es, quien tiene animus auctoris; mientras que sería partícipe quien actúa con la voluntad de ser partícipe, esto es, quien tiene animus socii. Los criterios para el animus auctoris son el querer el hecho como propio y el interés en el resultado del hecho. Los criterios para el animus socii son el querer el hecho como ajeno y la falta de interés en el resultado del hecho. 
A pesar de que hasta hoy la jurisprudencia mantiene esta doctrina subjetiva de la intervención delictiva, de la boca hacia afuera, para fundamentar sus decisiones más emblemáticas, la misma es enteramente inservible. En un derecho penal del hecho, que alguien sea autor o cómplice no puede ser exclusivamente dependiente de lo que él, subjetivamente, quiera. Si A dispara sobre B con un arma de fuego, el primero difícilmente podrá negar su autoría diciendo que ha ejecutado el hecho en interés exclusivo de un tercero. La prohibición del homicidio es válida con independencia de por qué motivo y en interés de quién alguien mate a otro ser humano. Además, hay una serie de delitos - por ejemplo, la extorsión, la estafa, el homicidio a requerimiento - en los cuales ya con arreglo al tenor literal de la ley también puede ser autor quien no actúa en interés propio sino ajeno.

\section{LA TEORÍA DEL DOMINIO DEL HECHO}

1. La doctrina actualmente dominante en la ciencia del derecho penal clasifica los hechos punibles en delitos de dominio y delitos de infracción de deber. Los delitos de infracción de deber son delitos que sólo pueden ser cometidos por determinadas personas, portadoras de un deber especial. En particular, aquí se trata de los delitos de funcionario público, así como de determinados delitos que presuponen una posición de garante. Quien infringe un tal deber especial es, por principio, autor. Todos los demás intervinientes que no son portadores de tal deber sólo pueden ser, a lo sumo, partícipes.

En los delitos de dominio, en cambio, la situación se presenta de modo enteramente distinto. Pues aquí el criterio determinante lo ofrece el así llamado dominio del hecho. Aquel que ostenta el dominio del hecho es autor; aquel que carece del mismo es partícipe. El dominio del hecho es definido, por su parte, por referencia a un dominio de decisión y a un dominio de configuración. Tiene dominio de decisión aquel de quien depende si el hecho se comete o no. Tiene dominio de configuración aquel que puede determinar cómo es ejecutado el hecho en sus particularidades. En todo caso, estos criterios de dominio del hecho se articulan diferenciadamente en atención a cada una de las específicas formas de autoría.

Mientras que el autor directo, en cierta medida, tiene un total dominio del hecho, los coautores sólo ejercen un dominio funcional del hecho. El dominio funcional supone un proceder bajo condiciones de división del trabajo, en cuyo marco los coautores ejercitan una medida esencialmente equivalente de dominio del hecho. Un plus de dominio de decisión puede compensar un minus de dominio de configuración, y viceversa.

De modo completamente distinto se determina el dominio del hecho en la autoría mediata. Aquí sería decisivo que el autor manipule al hombre de adelante, su "instrumento" humano. Y cabría reconocer tres posibilidades de instrumentalización: 
Primero: si en la ejecución del hecho por el hombre de adelante falta un presupuesto de la realización culpable de un tipo delictivo, por ejemplo, por encontrarse bajo un error, o bien porque actúa justificada o inculpablemente. Este déficit de un presupuesto de la punibilidad es aprovechado por el hombre de atrás; por ejemplo, el hombre de atrás pone al hombre de adelante en una situación de error de tipo excluyente del dolo.

Segundo: si el hombre de atrás se aprovecha de que el hombre de adelante se encuentra bajo un error de motivación que sea de peso; por ejemplo, el hombre de adelante daña una vasija ajena de alto valor que él, en virtud de un engaño del hombre de atrás, tiene por carente de valor.

Tercero: si el hombre de atrás dirige al hombre de adelante, valiéndose de rígidas formas de organización, o bien de procedimientos estrictamente reglados. De esta manera, el posicionado más arriba en una forma de estado dictatorial, en una organización criminal o una gran empresa económica podría controlar, al modo de un "autor detrás del autor", el comportamiento del ejecutor subordinado.

2. A la vista de estos criterios llamativamente dispares para la autoría, se plantea la pregunta de qué cabe entender, efectivamente, como el elemento común para este dominio del hecho. ¿Cómo podrían fundamentar fenómenos tan distintos, e incluso opuestos - como por ejemplo la utilización de un déficit de responsabilidad o la división del trabajo -, una competencia por el comportamiento de otra persona suficiente para fundamentar la autoría? Es decir: ¿qué significa exactamente, desde el punto de vista del derecho penal, un "dominio del hecho"? La teoría del dominio del hecho sostiene que sería autor quien "tiene en la mano" el suceso realizador del tipo, quien aparece como la "figura central del suceso", mientras que sería mero partícipe quien sólo interviene en el margen. "Figura central" y "figura marginal" son imágenes cautivadoras, pero están lejos de constituir categorías dogmáticas. Que en derecho penal no se trata de la posición fáctica de un sujeto cualquiera, lo muestran claramente los delitos de infracción de deber, en los cuales es autor quien carga con la responsabilidad normativa por la producción el suceso.

En lo que sigue - y a través de una revisión crítica de la teoría del dominio del hecho - se esbozará un modelo normativo para la sistematización de la intervención delictiva. Para ello quisiera, por de pronto, analizar la conexión entre norma y acción con la vista puesta en el caso básico de un delito de resultado cometido por un autor individual de propia mano. Sobre esta base serán brevemente examinadas, entonces, las cuestiones ulteriores relativas a la autoría mediata, la coautoría, la participación y la imprudencia.

\section{NORMA, ACCIÓN, DEBER}


1. Consideremos en un primer paso, ahora, la relación en que se encuentran los conceptos de norma y acción, conectados entre sí a través del concepto de deber. El derecho penal protege bienes jurídicos a través de normas. Las normas, a su vez, son seguidas a través de acciones. En el análisis del concepto de acción, tiene sentido contraponer éste al concepto de comportamiento. Con la expresión "comportamiento" puede designarse el movimiento espacio-temporalmente situado de un ser vivo. Circunscribiendo el punto a seres humanos: alguien corre, levante su brazo o duerme. Un comportamiento es, en otras palabras, un suceso causal. Una acción, en cambio, es un comportamiento interpretado intencionalmente. La adscripción de una acción provee una explicación de por qué alguien se ha comportado de determinada manera. En una explicación tal se recurre a intenciones. Por ejemplo: A dispara con su arma sobre B, porque quiere matarlo. Así, las adscripciones de acciones conectan un comportamiento (aquí: el disparar el arma) y un cambio en el mundo (aquí: la muerte de B), de modo tal que el comportamiento pasa a ser entendido como medio para la producción del cambio intencionalmente perseguido.

Tales cambios o variaciones del mundo también pueden ser objetos intencionales de comportamientos pasivos. Yo no me comporto de una determinada manera, por ejemplo, para así dejar que se produzca un cambio que de lo contrario no se habría producido, o bien para dejar sin producirse un cambio que de lo contrario sí se habría producido. A modo de ejemplo: A no dispara contra B, para que así éste no muera. Las interpretaciones intencionales de formas de comportamiento pasivo en relación con un cambio intencionalmente perseguido, se denominan omisiones.

2. El derecho penal protege bienes jurídicos frente a la producción de cambios desfavorables, o frente a la no-producción de cambios favorables, por la vía de la producción de normas. A través de prohibiciones se proscriben formas de comportamiento que producen cambios desfavorables o impiden cambios favorables. Y a través de mandatos se prescriben formas de comportamiento que producen cambios favorables o impiden cambios desfavorables. En consecuencia, son antinormativos aquellos comportamientos que no se ajustan a la correspondiente prohibición o mandato. Consideremos esto más de cerca, de la mano de una prohibición de la producción de un cambio perjudicial para un bien jurídico, que podemos llamar "resultado".

Asumamos que A dispara con su arma de fuego contra B, y a través de esto condiciona su muerte. En tal caso, a través de su comportamiento A ha producido causalmente la muerte de $\mathrm{B}$, es decir, ha realizado el injusto de resultado de un homicidio. Pero A sólo portará responsabilidad por este comportamiento antinormativo, si él hubiese podido evitarlo en pos del seguimiento de la norma. Pues de acuerdo con el principio "ultra posse nemo obligatur", el destinatario de la prohibición del homicidio sólo queda vinculado a esta norma en la medida de su propia capacidad de acción. Esta vinculación a una norma con arreglo a la medida de la propia capacidad puede denominarse "deber". Esto significa que la causación 
de la muerte de otro resulta contraria a deber si el sujeto en cuestión estaba en posición de omitir su comportamiento causal para así evitar la producción del resultado mortal. Los criterios de la capacidad de acción están constituidos por los conocimientos y las capacidades físicas que son necesarios para poder realizar, a través del propio comportamiento, la intención de evitar la producción del resultado.

En el caso del ejemplo, A era capaz de acción en la medida en que él sabía de la situación fáctica y de las conexiones causales relevantes, esto es, sabía que su arma estaba cargada, que B era un ser humano vivo, etc. Adicionalmente, él tiene que haber sido físicamente capaz de controlar su cuerpo. El movimiento del dedo no puede haber correspondido, por ejemplo, a un espasmo incontrolado. Si A cumple con estos presupuestos de la capacidad de acción, esto es, si él dispone del saber suficiente y de la capacidad física imprescindible para omitir el disparo y evitar así la producción de la muerte de $\mathrm{B}$, entonces él es portador del deber de omitir este comportamiento peligroso para la vida de B.

El concepto de deber expresa la vinculación del destinatario a la norma en atención a su propia capacidad de acción. Esto quiere decir, a la inversa: si A mata a $\mathrm{B}$ habiendo sido capaz de realizar la intención de evitar dar muerte a $\mathrm{B}$ a través de su comportamiento, entonces a él resulta imputable su comportamiento a título de infracción de deber. En la sistemática del delito, la dimensión intelectual de la capacidad de acción es objeto de comprobación bajo la etiqueta "dolo". Y la infracción de deber puede ser designada como el injusto (subjetivo) de la acción típicamente relevante.

El reproche de haber quebrantado la prohibición del homicidio consiste, entonces, en que alguien no ha evitado intencionalmente la causación de la muerte de otro ser humano, a pesar de haber sido capaz de hacerlo. Cuál sea el motivo por el cual alguien ha puesto una causa para la muerte de otro, es enteramente irrelevante bajo la prohibición del homicidio. No necesita en modo alguno tratarse de un comportamiento finalmente dirigido a la producción de la muerte. $\mathrm{Al}$ autor sólo se reprocha haber causado la muerte de otro a través de su comportamiento, a pesar de que él habría podido evitarlo en pos del seguimiento de la norma.

3. De esto resulta lo siguiente: si el dominio del hecho se identifica con la capacidad de acción necesaria para evitar la realización del tipo, entonces es claro que el dominio del hecho sólo puede estar referido al propio comportamiento contrario a deber, y nunca a un comportamiento contrario a deber de alguna otra persona. Es perfectamente posible que otro sólo pueda cometer una infracción de deber en caso que yo efectúe una contribución al efecto. Pero entonces mi dominio del hecho también se reduce, exclusivamente, a que puedo evitar, a través de mi comportamiento, una causación del resultado. En ningún caso puedo dominar, a través de mi contribución, una infracción de deber ajena. Pues la infracción de deber ajena se encuentra justamente definida por el hecho de que ella resultaba evitable para el otro también obligado. 
A modo de ejemplo: si el ladrón L cuenta con que yo le proporcione la combinación de una caja fuerte, entonces yo puedo impedir que el ladrón abra la caja fuerte, si no le doy la clave. Pero esto ciertamente no significa que a través del suministro de la clave yo domine, en un sentido positivo, la apertura de la caja fuerte por parte del ladrón. Pues la apertura de la caja fuerte es un comportamiento que, en el caso concreto, sólo el ladrón está en posición de realizar.

Esto también vale, sin reserva alguna, tratándose de delitos compuestos o de varios actos. Si A amarra a O, para que así B pueda sustraerle el maletín, A y B pueden ser - por razones que habrá que analizar todavía - coautores de un robo. Pero la razón para esto no es que cada uno de ellos tuviera dominio sobre todo el hecho en su conjunto. $\mathrm{B}$ no ha amarrado a $\mathrm{O}$, y $\mathrm{A}$ nada ha sustraído. En consecuencia, $\mathrm{B}$ no podía, de modo conforme a deber, omitir amarrar a $\mathrm{O}$, así como A tampoco podía, de modo conforme a deber, omitir la sustracción. En la medida en que la teoría del dominio sostiene algo distinto, ella finge hechos y atenta así contra el principio de culpabilidad.

De estas reflexiones se sigue: el dominio del hecho, en sentido negativo, no puede servir de criterio para la demarcación entre autoría y participación. Pues cada interviniente que pone una causa para el resultado, sea autor o partícipe, puede de hecho, a través de la evitación de esta contribución casual, evitar el concreto suceso conducente al resultado en su conjunto. Pero el dominio del hecho, en sentido positivo, tampoco puede servir de criterio de demarcación, ya que mi propio comportamiento contrario a deber no puede estar dominado, al mismo tiempo, por mí y por otro. Así, la diferencia entre autoría y participación sólo puede hallarse en el propio comportamiento en cuestión, esto es, en la manera precisa en que el resultado es causado por el respectivo comportamiento. Ello significa: a través del comportamiento del autor el resultado es causado de una manera distinta a como el mismo es causado a través del comportamiento del partícipe.

4. De ningún modo quisiera introducir aquí un concepto especial de causalidad. Antes bien, me gustaría explicar mi tesis de la mano de aquellos conceptos con los cuales el derecho penal describe el comportamiento antinormativo tratándose de delitos dolosos de comisión activa, como por ejemplo con verbos tales como "matar", "lesionar", "dañar", "sustraer", etcétera.

Quedémonos con el verbo "matar": si yo proporciono un cuchillo a A, con el cual éste perfora letalmente a $B$, entonces cabe decir: "A ha matado a B mediante la perforación con el cuchillo". En cambio, sería lingüísticamente anómalo decir: "he matado a $\mathrm{B}$ al darle a $\mathrm{A}$ el cuchillo con el cual éste perforó a B". A pesar de que tanto el comportamiento de A como mi comportamiento han sido causales para la muerte de B, sólo el comportamiento causal de Ase deja describir como "matar". ¿Por qué? 
Mediante verbos como "matar", "lesionar", "dañar", etcétera, la conexión causal entre comportamiento y resultado es interpretada como una conexión inmediata, que uno puede expresar con ayuda de una relación del tipo "por el hecho de/que". En el ejemplo: "A mató a B por el hecho de que él lo perforó con un cuchillo". Mi comportamiento, en cambio, no se deja conectar con el resultado a través de una relación del tipo "por el hecho de/que". Pues B no ha muerto por el hecho de que yo proveyera de un cuchillo a A. Es recién mediadamente, través del comportamiento de $\mathrm{A}$, que mi comportamiento se vuelve causalmente relevante para la muerte de B. Sólo puede hablarse de matar, en consecuencia, en el caso de una causación inmediata del resultado de muerte a través de un determinado comportamiento.

\section{AUTORÍA MEDIATA}

1. Existe la posibilidad, sin embargo, de atribuir a una persona, como actuar propio, la causación del resultado a través de otra persona. ¿Cómo se deja construir una tal autoría mediata? Establezcamos, por de pronto, lo siguiente: si alguien se comporta de una manera que bajo una determinada descripción resultaba intencionalmente evitable para él, entonces sólo él ostenta el dominio fáctico de este comportamiento. Un dominio del hecho sobre otro sólo es posible por la vía de una vis absoluta, y esto constituye, a su vez, una forma de autoría directa. Si empujo a alguien al suelo, quien al caer daña la cosa de un tercero, entonces he sido yo quien ha dañado la cosa en autoría directa. La autoría mediata, en cambio, concierne aquellos casos en que mi quebrantamiento de la norma resulta mediado por el comportamiento intencionalmente evitable de un tercero.

Por ello, el dominio del hecho, en un sentido fáctico, no puede ser un criterio de autoría mediata. Antes bien, la autoría mediata sólo puede ser fundamentada normativamente, y ya justamente en el sentido de que el hombre de adelante actúa en el lugar del hombre de atrás, o más precisamente: que al hombre de atrás resulta atribuible el comportamiento del hombre de adelante como comportamiento propio. $\mathrm{Y}$ aquí hay que atender, por su parte, a un principio fundamental de la imputación: la responsabilidad jurídico-penalmente relevante no puede ser transferida, a modo de exoneración, de una persona a otra. Yo no puedo matar a otro de modo plenamente responsable y después transferir mi responsabilidad a un tercero con la consecuencia de que sólo el tercero fuese responsable en mi lugar. Puede ser que un tercero resulte de algún modo coresponsable por mi comportamiento - la coautoría, la complicidad y la inducción descansan en este principio de responsabilidad derivativa. Pero estas formas de intervención delictiva jamás pueden conducir a la exoneración de un sujeto efectivamente responsable.

Siendo esto así, al hombre de atrás sólo puede resultar imputable el comportamiento del hombre de adelante, como un comportamiento propio por el 
cual el primero puede cargar responsabilidad, si la responsabilidad del hombre de adelante es deficitaria. Y aquí el déficit puede encontrarse referido a cualquiera de los presupuestos de la responsabilidad jurídico-penal, es decir, a un elemento de la tipicidad, del injusto o de la culpabilidad. Pero el déficit ha de encontrarse referido precisamente a uno de los presupuestos bajo los cuales el hombre de atrás, a su vez, responde por el comportamiento como propio. A modo de ejemplo: si yo vierto un veneno mortal en el coñac de mi enemigo $\mathrm{E}$, que éste bebe sin tener noción alguna de aquella circunstancia, entonces $\mathrm{E}$ carga sin más autoresponsabilidad por su comportamiento bajo la descripción "beber coñac". Pues bajo esta descripción, E podía omitir intencionalmente su comportamiento, en caso que él no hubiese querido beber coñac. En cambio, él actúa deficitariamente bajo la descripción en términos de la cual es a mí a quien resulta imputable el comportamiento como quebrantamiento de la prohibición del homicidio. Pues en virtud de su falta de conocimiento del veneno, E no podía evitar su comportamiento bajo la descripción "beber coñac envenenado".

2. Como segundo requisito de la autoría mediata, el hombre de atrás ha de satisfacer todos los presupuestos bajo los cuales a él podría resultar imputable el comportamiento del hombre de adelante, atribuido como comportamiento propio, a título de quebrantamiento de la norma. Esta exigencia se entiende de suyo, en tanto el hombre de atrás ha de ser autor y por ello satisfacer todos los presupuestos del delito en su propia persona. A modo de ejemplo: en un delito especial de funcionario público, el hombre de atrás tiene que ser funcionario.

3. Finalmente, es necesario que exista una conexión entre el déficit que afecta al hombre de adelante y la imputación de su comportamiento al hombre de atrás. Tiene que existir una razón para la imputabilidad de este comportamiento. En la dogmática alemana se afirma a veces que como fundamento para esta imputación sería suficiente un saber superior de parte del hombre de atrás. Pero de ser así, en este mundo los mejor informados tendrían que cargar responsabilidad por los desinformados, con lo cual dejaría de ser posible una distribución de ámbitos de responsabilidad fundada en la idea normativa de igualdad. Un mero saber superior sólo puede obligar a una solidaridad social mínima, y en derecho penal esto quiere decir: en el sentido de los delitos de omisión de socorro o de omisión de denuncia de la comisión inminente de un hecho punible.

En la autoría mediata, como fundamento de la imputación sólo viene en consideración una intervención no permitida en la esfera de responsabilidad del hombre de adelante, ya sea a través de coacción, a través del condicionamiento o sostenimiento de un error, o en virtud de un vínculo de solidaridad especial en el sentido de una posición de garante. Así por ejemplo, yo soy autor mediato si vierto veneno en el coñac de mi enemigo E. Pues el hecho de que E yerre acerca de la cualidad de su bebida se debe a mi manipulación del objeto de su representación.

\section{COAUTORÍA}


1. Examinemos ahora la pregunta acerca de la base normativa sobre la cual puede hacerse descansar la coautoría. Por de pronto, hay que establecer que la coautoría se diferencia de la autoría directa individual por el hecho de que cada uno de los intervinientes no necesita haber causado inmediatamente el resultado típico. Más bien, la coautoría también es posible, como lo muestra el ejemplo del robo ya mencionado, cuando cada uno de los dos intervinientes sólo realiza, inmediatamente, un fragmento parcial de un suceso típico global. Y una coautoría puede incluso venir en consideración si uno de los intervinientes sólo indirectamente contribuye a la causación del resultado.

Frente a la autoría mediata, la coautoría se distingue por el hecho de que ninguno de los intervinientes exhibe un déficit de imputación del cual tenga que responder otro interviniente; de lo contrario, él no podría ser autor en relación con el otro. Pero si cada uno porta responsabilidad frente a los demás intervinientes, esto es, siendo cada uno capaz de acción para la evitación del propio comportamiento contrario a deber, entonces también en la coautoría ha de ser normativamente fundamentada la responsabilidad por un comportamiento ajeno. Pues ninguno de los intervinientes tiene dominio del hecho sobre los demás, y así tampoco tiene dominio, en sentido positivo, sobre el hecho en su conjunto. La capacidad de acción que fundamenta la autoría es, desde un punto de vista fáctico, irreduciblemente individual.

De ello se sigue que la coautoría depende de dos presupuestos: primero, cada uno de los intervinientes ha de ser responsable por el propio comportamiento, independientemente de los demás; y segundo, a cada uno de los intervinientes ha de ser normativamente imputable el comportamiento de los demás como comportamiento propio.

La posibilidad de la imputación de un comportamiento ajeno como propio constituye algo obvio para el derecho. En el derecho civil, por ejemplo, la figura de imputación de la representación descansa en este principio. Otro puede vincularme a través de su comportamiento realizado en mi nombre, como si yo mismo hubiese efectuado la declaración de voluntad en cuestión. Esto se conoce, precisamente, como el principio de la representación.

La coautoría también se funda en el principio de la representación. Por contraposición a la simple representación, sin embargo, aquí aparece una peculiaridad. Para que cada uno pueda ser competente por el suceso global, cada cual ha de ser responsable, primero, por el propio comportamiento y al mismo tiempo ser representado a través del comportamiento ajeno. Así, los coautores tienen que representarse recíprocamente, en tanto ellos efectúen su contribución al hecho tanto para sí, en nombre propio, como para los demás, en nombre ajeno.

2. La representación presupone, a su vez, el reconocimiento de un cometido correspondiente. Esto significa: los coautores han de actuar, subjetivamente, sobre 
la base de una plan conjunto. O - como uno también podría decir - en su comportamiento han de moverse dentro de un esquema común de interpretación. Aquel que abandona este esquema comete un exceso, y en tal medida deja de representar a los demás intervinientes.

Adicionalmente, la contribución al hecho de cada interviniente también ha de ser "representativa". Aquí yace el núcleo sensato de la teoría del dominio del hecho referida al principio de división funcional del trabajo. Quien sólo colabora en el margen no es alguien que de un modo exteriormente expresivo represente el hecho como propio, esto es, alguien que de un modo relevante quiera dar la cara por el quebrantamiento de la norma. En otras palabras, una división funcional del trabajo es presupuesto objetivo de una representación relevante para la coautoría. Pues el autor no es meramente llamado a responder por un déficit de fidelidad al derecho, sino ya también por la realización objetiva del injusto.

\section{INDUCCIÓN Y COMPLICIDAD}

Sobre la base de las reflexiones precedentes es posible determinar, sin mayores dificultades, los criterios con arreglo a los cuales puede demarcarse la participación frente a la autoría. En esta delimitación, el concepto de autoría resulta decisivo, es decir, la participación presupone que la intervención en cuestión no constituya autoría. Habiéndose establecido negativamente que no se da una autoría, entonces ha de comprobarse, en un segundo paso, si se satisfacen los presupuestos positivos de alguna de las dos formas de participación. En este sentido, la inducción ha de delimitarse negativamente frente a la autoría mediata, mientras que la complicidad se diferencia negativamente de la coautoría. En particular, esto significa lo siguiente:

(1) Autor de propia mano es siempre aquel que lesiona individualmente el deber que resulta de la norma. En los delitos puros de resultado, se trata de aquel que produce el resultado por el hecho de comportarse de determinada manera, en circunstancias que él habría podido evitarlo en atención a su capacidad de acción. La autoría mediata y la coautoría representan ampliaciones normativas de la autoría de propia mano.

(2) En la autoría mediata, una persona distinta del autor realiza el comportamiento que realiza el tipo. Pero esta persona no es en sí misma responsable por este comportamiento realizador del tipo, ya que aquí ha de fallar un presupuesto necesario del carácter delictivo de su comportamiento. Y este comportamiento resulta, a su vez, imputable al hombre de atrás, siempre que él, en primer lugar, sea competente por el déficit de responsabilidad del hombre de adelante y, en segundo lugar, cumpla en su propia persona todos los demás presupuestos típicos.

Por ende, no se da una autoría mediata, sino sólo una inducción, si el hombre de atrás ha motivado determinante el comportamiento del hombre de 
adelante, pero sin ser competente por un déficit de un presupuesto constitutivo para el delito correspondiente.

(3) En la coautoría resultan vinculadas formas de comportamiento en la configuración de un hecho conjunto, que es imputable a cada uno de los coautores, en la medida en que los intervinientes se hayan representado recíprocamente, en el marco de un esquema común de interpretación, en la realización del tipo.

Por ende, no se da una coautoría, sino sólo una complicidad, si uno de los intervinientes no actúa en razón de un plan conjunto del hecho, o bien no efectúa una contribución representativa.

\section{IMPRUDENCIA}

1. Para concluir, resta preguntarse sucintamente por qué la imprudencia sólo conoce un autor unitario. El autor imprudente, en contraposición al autor doloso, cuenta con una limitada capacidad de evitación. Por ejemplo, por estimar como demasiado bajo el riesgo de una realización del tipo, o bien por desconocerlo completamente. Pero por este desconocimiento o estimación errada él mismo puede ser hecho responsable, puesto que, de haber observado el cuidado esperable, él habría juzgado correctamente la situación y con ello habría asegurado su propia capacidad de acción.

Es decir, de haber observado el cuidado necesario, el autor imprudente habría sido capaz de evitación al momento en que tuvo lugar el comportamiento realizador del tipo, en circunstancias en que de facto no lo fue. En tal medida, en la imprudencia ya no se da el caso básico de la autoría de propia mano (la cual requiere la capacidad actual de evitación del destinatario de la norma). Justamente por esto, los tipos de delito imprudente del Código Penal alemán se hallan formulados de manera distinta a los tipos de delito doloso. Así por ejemplo, no se habla aquí de "el que mate a otro", sino de "el que cause la muerte de otro".

Con esta formulación más amplia del "causar imprudente" se ve comprehendida toda contribución que en el caso del delito doloso caería bajo la forma de una autoría o de una participación. Y esto significa: en los delitos imprudentes tampoco resulta relevante la diferenciación entre causación directa y causación mediada a través de un tercero. Es decir, que yo dispare imprudentemente contra otro o sólo provea de un arma a un tercero, sin representarme que éste pretende matar a un tercero usando el arma, no representa diferencia alguna para la afirmación de un homicidio imprudente con arreglo al derecho alemán. 